\title{
A transgenic rabbit model for human hypertrophic cardiomyopathy
}

\author{
Ali J. Marian, Yun Wu, Do-Sun Lim, Meghan McCluggage, Keith Youker, Qun-tao Yu, \\ Ramon Brugada, Francesco DeMayo, Miguel Quinones, and Robert Roberts
}

Section of Cardiology, Department of Medicine, Baylor College of Medicine, Houston, Texas 77030, USA

Address correspondence to: A.J. Marian, Section of Cardiology, One Baylor Plaza, 543E, Houston, Texas 77030, USA.

Phone: (713) 798-7454; Fax: (713) 798-3147; E-mail: amarian@bcm.tmc.edu.

Received for publication July 23, 1999, and accepted in revised form October 29, 1999.

\begin{abstract}
Certain mutations in genes for sarcomeric proteins cause hypertrophic cardiomyopathy (HCM). We have developed a transgenic rabbit model for HCM caused by a common point mutation in the $\beta$ myosin heavy chain $(\mathrm{MyHC})$ gene, R400Q. Wild-type and mutant human $\beta$-MyHC cDNAs were cloned $3^{\prime}$ to a $7-\mathrm{kb}$ murine $\beta$-MyHC promoter. We injected purified transgenes into fertilized zygotes to generate two lines each of the wild-type and mutant transgenic rabbits. Expression of transgene mRNA and protein were confirmed by Northern blotting and 2-dimensional gel electrophoresis followed by immunoblotting, respectively. Animals carrying the mutant transgene showed substantial myocyte disarray and a 3-fold increase in interstitial collagen expression in their myocardia. Mean septal thicknesses were comparable between rabbits carrying the wild type transgene and their nontransgenic littermates (NLMs) but were significantly increased in the mutant transgenic animals. Posterior wall thickness and left ventricular mass were also increased, but dimensions and systolic function were normal. Premature death was more common in mutant than in wild-type transgenic rabbits or in NLMs. Thus, cardiac expression of $\beta-\mathrm{MyHC}-\mathrm{Q}^{403}$ in transgenic rabbits induced hypertrophy, myocyte and myofibrillar disarray, interstitial fibrosis, and premature death, phenotypes observed in humans patients with HCM due to $\beta-M y H C-Q^{403}$.
\end{abstract}

J. Clin. Invest. 104:1683-1692 (1999).

\section{Introduction}

HCM is a relatively common disease (1) that is diagnosed by the presence of left ventricular hypertrophy in the absence of an increased external load (2). The pathology is characterized by myocyte hypertrophy, disarray, and increased interstitial collagen (3). Patients with HCM exhibit protean clinical manifestations that range from an asymptomatic phenotype to those of severe heart failure and sudden cardiac death (SCD) (2). HCM is the most common cause of SCD in the young, particularly athletes, accounting for $35 \%$ of SCD in young competitive athletes (4).

Mutations in 8 genes, all encoding sarcomeric proteins, have been identified in patients with HCM (reviewed in ref. 5). The most common gene responsible for human HCM is the $\beta-\mathrm{MyHC}$, which accounts for $35-50 \%$ of HCM cases (6). The causality of mutant sarcomeric proteins, including mutant $\beta-\mathrm{MyHC}$, in HCM is well established (reviewed in ref. 7). The research emphasis has now shifted toward elucidation of the molecular pathogenesis of HCM phenotypes with the hope of identifying new therapeutic targets. Studies in a variety of in vitro models, including cardiac myocytes, allude to diversity of the initial defects (reviewed in ref. 8), by which mutant proteins can impair cardiac myocyte structure and function (9-11). Genetic animal models have been generated, primarily transgenic mice, expressing a variety of mutant sar- comeric proteins (12-19). The phenotypes have been premature death, cardiac myocyte disarray, interstitial fibrosis, and systolic and diastolic dysfunction. However, left ventricular hypertrophy, the hallmark of HCM in humans, is usually minimal or absent (12-19). Global left ventricular systolic function is also commonly impaired in adult transgenic mice $(13,14$, 19). In human patients with HCM, although there is often regional impairment of ventricular systolic function (20-23), global left ventricular function, as assessed by the ejection fraction, is usually maintained within normal limits (2). Experimental studies suggest that hypertrophy in humans with HCM is compensatory (reviewed in ref. 7) and responsible for maintaining the normal ventricular ejection fraction (23). Impaired systolic function in the transgenic mouse models expressing mutant sarcomeric proteins may reflect the minimal hypertrophic response.

Another major concern with the mouse as a model for human HCM, particularly for HCM caused by the $\beta$ $\mathrm{MyHC}$ mutations, is the presence of major differences in the composition of cardiac sarcomeric proteins between humans and mice. The murine cardiac ventricle has predominately $\alpha-\mathrm{MyHC}$, as opposed to human ventricle, which predominately has $\beta$-MyHC (24). Because the $\mathrm{MyHC}$ isoforms exhibit significant differences in actinactivated-Mg-ATPase activity and cross-bridge kinetics (25-29), differences is cardiac sarcomeric protein com- 
position can affect the phenotypic response of the heart to mutant proteins. In contrast to the mouse, the predominant myosin isoform in the rabbit myocardium is $\beta$-MyHC (30), which has an approximately $98 \%$ homology to human $\beta$-MyHC protein $(30,31)$. Therefore, we generated a transgenic rabbit model for human HCM, by expressing the mutant $\beta$-MyHC-Q ${ }^{403}$ protein, known to cause HCM in humans (32), in the heart. The phenotype was virtually identical to that of humans, namely, premature death, cardiac hypertrophy, myocyte disarray, interstitial fibrosis, and normal systolic function.

\section{Methods}

All protocols used in this study were approved by the Institutional Review Board of Baylor College of Medicine.

Transgenes. Previously cloned wild-type $\left(\mathrm{R}^{403}\right)$ and mutant $\left(\mathrm{Q}^{403}\right)$ full-length $(6-\mathrm{kb})$ human $\beta$-MyHC cDNAs (33) were inserted into SalI and HindIII restriction enzyme sites downstream to a $7-\mathrm{kb} 5^{\prime}$ fragment of the murine $\beta$-MyHC gene (clone 32; kindly provided by J. Robbins [University of Cincinnati, Cincinnati, Ohio, USA]). The 7- $\mathrm{Kb} \beta-\mathrm{MyHC}$ promoter also contains the first 3 noncoding exons and the corresponding introns of the $\beta$-MyHC gene. In addition, a 600 -bp fragment of the $3^{\prime}$ untranslated (UT) fragment of human growth hormone (hGH) was positioned $3^{\prime}$ to the human $\beta$ $\mathrm{MyHC}$ cDNAs to enhance mRNA stability (Figure 1).

Generation of transgenic rabbits. The entire transgenes $(\beta$ $\mathrm{MyHC}$ promoter $+\beta-\mathrm{MyHC} \mathrm{cDNA}+3^{\prime} \mathrm{UT}$ hGH) were released from the vector by NotI restriction endonuclease digestion, separated by gel electrophoresis, purified free from the vector, and diluted in TE buffer at the concentration of $100 \mathrm{ng} / \mu \mathrm{L}$. The procedure to produce transgenic rabbits was similar to that described by Knight et al. (34). In brief, on day -4 , zygote donor rabbits were injected subcutaneously with $50 \mathrm{IU}$ of pregnant mare serum gonadotropin to induce superovulation. Female donor rabbits were then mated with stud male rabbits to produce fertilized zygotes. Nineteen hours later, on day 1 , single-cell embryos were flushed from donor rabbits' oviducts in medium consisting of PBS supplemented with $20 \% \mathrm{FBS}$ at $\mathrm{pH}$ 7.4. The pronuclei of fertilized zygotes were microinjected with purified linearized $\beta$-MyHC transgene constructs. Female recipient rabbits were made pseudopregnant by intravenous injection of $150 \mathrm{IU}$ of chronic gonadotropin and mating with vasectomized sterile male rabbits 2 days before implantation. After microinjection, the 1-cell embryos were implanted through the fimbrial end of the oviducts of

\section{Figure 1}

Schematic illustration of wild-type $\left(\beta-\mathrm{MyHC}-\mathrm{R}^{403}\right)$ and mutant $(\beta$ $\left.\mathrm{MyHC}-\mathrm{Q}^{403}\right)$ transgene constructs. Wild-type and mutant human cDNAs were cloned $3^{\prime}$ to a $7-\mathrm{kb}$ murine mutant $\beta-\mathrm{MyHC}$ promoter. A 600-bp 3' untranslated fragment (UT) of human growth hormone $(\mathrm{hGH})$ was also placed downstream to the cDNAs. recipient rabbits under general anesthesia. The recipient rabbits were monitored for signs of pregnancy and birth of the bunnies for 2 months after implantation.

Identification of transgenic rabbits and establishing transgenic lines. Newborn bunnies were screened for the presence of transgene DNA by PCR and Southern blotting. DNA was extracted from ear biopsies using a DNA extraction kit (Qiagen Inc., Valencia, California, USA). Based on the sequence of the transgene (31), a set of oligonucleotide primers was designed (forward 5'-TGAGCATTCTCCTGCTGTTTC- $3^{\prime}$ and reverse 5'-CTCATGCAGGAAGGTCAGC-3') to amplify a 750-bp fragment of the transgene. PCR products were also sequenced using an automated $\mathrm{ABI} 310$ sequencer for verification.

Southern blot analysis was performed as described previously (35). In brief, $10 \mu \mathrm{g}$ of genomic DNA was digested with $\mathrm{Bam} \mathrm{H} 1$ restriction endonuclease, which releases a $1.3-\mathrm{kb}$ fragment of the transgenes. After agarose gel-electrophoresis, DNA was transferred to a nylon membrane and was hybridized with an 800-bp $\left[{ }^{32} \mathrm{P}\right] \mathrm{dCTP}$ (Amersham Corp, Arlington Heights, Illinois, USA) labeled fragment of human $\beta$-MyHC cDNA in hybridization buffer $(6 \times$ SSC, $0.5 \%$ SDS, and 100 $\mu \mathrm{g} / \mathrm{mL}$ of denatured salmon sperm DNA) in Denhardt's solution $(0.1 \%$ Ficoll, $0.1 \%$ polyvinylpyrrolidone, $0.1 \% \mathrm{BSA}$ ) at $65^{\circ} \mathrm{C}$ overnight. The next day, membrane was washed under stringent conditions $(1 \times \mathrm{SSC}$, $0.1 \%$ SDS at room temperature, followed by 3 washes at $68^{\circ} \mathrm{C}$ in $0.2 \times \mathrm{SSC}$ and $0.1 \% \mathrm{SDS}$ ), and signals were detected by autoradiography.

Northern blot and RT-PCR. Northern blotting was performed to detect and compare expression levels of the transgenes mRNAs as described previously (36). In brief, total RNA was isolated by guanidinium thiocyanate method (37), and $20-\mu \mathrm{g}$ aliquots of total RNA extracts were loaded onto formaldehyde-agarose gels, subjected to electrophoresis, and transferred to nylon membranes (Zeta Probes; Bio-Rad Laboratories, Hercules, California, USA). A total of $100 \mu \mathrm{M}$ of transgenespecific oligonucleotide primer (5'-GCTGTTGAAATCGAAGATCTCG-3') was end-labeled with $\left[\gamma^{3}{ }^{32}\right.$ P]ATP (Amersham Corp.) using 5 units of T4 polynucleotide kinase (Life Technologies, GIBCO BRL, Rockville, Maryland, USA). The radiolabeled probe was hybridized to mRNAs in the presence of Denhardt's reagents in hybridization buffer $(5 \times$ SSPE, $0.1 \%$ SDS, $50 \%$ formamide, $100 \mu \mathrm{g} / \mathrm{mL}$ of denatured salmon sperm DNA) at $42^{\circ} \mathrm{C}$ overnight. Membranes were then washed and exposed to $\mathrm{x}$-ray films as already described here.

\begin{tabular}{|c|c|c|}
\hline \multicolumn{3}{|c|}{ B-MyHC-R ${ }^{403}$ (Wild-type) } \\
\hline Murine $\beta-\mathrm{MyHC}$ & Human $\beta$-MyHC cDNA & hGH-3'UT \\
\hline \multicolumn{3}{|c|}{$\beta-M y H C-Q^{403}$ (Mutant) $Q_{1}^{403}$} \\
\hline Murine $\beta$-MyHC & Human $\beta$-MyHC cDNA & hGH-3'UT \\
\hline
\end{tabular}




\section{Figure 2}

Expression of the transgene mRNA in cardiac and noncardiac tissues. (a) Expression of the full-length transgene mRNA in the heart detected by Northern blotting. Lane 1 represents a positive control (human heart), lane 2 represents a negative control (nontransgenic rabbit), lanes 2 and 3 represent 2 lines of wild-type mutant transgenic rabbits, and lanes 4 and 5 represent 2 lines of mutant transgenic rabbits. As shown, a 6-kb band was detected in lanes 1 (positive control) and 2-6 (transgenic rabbits), but it was absent in lane 2 (a negative control). The lower blot represents GAPDH mRNA, which was used to control for loading conditions. (b) Expression pattern of the endogenous $\beta-\mathrm{MyHC}$ mRNA in noncardiac tissues in a nontransgenic littermate (NLM) rabbit detected by RT-PCR. RT controls (RT-), genomic DNA (labeled as DNA), and a PCR negative control (-control) are also included. As shown, a 368-bp RT product was present in lanes representing left ventricle (LV), left atrium (LA), and skeletal muscles (SK) after RT, but was absent in lanes representing lungs and aorta. (c) Expression pattern of the transgene mRNA in noncardiac tissues. Transgene construct and a human heart (HH) sample were included as positive controls and RT- and PCR negative controls were included as negative controls. As shown, a 340-bp band was present in lanes representing transgene (positive control), $\mathrm{HH}$ (positive control), LV, LA, and SK after RT. It was absent in lanes representing lungs and aorta.
To detect expression of the transgene mRNA in noncardiac tissues, we performed RT-PCR, using an approach previously used to detect expression of the mutant $\beta$-MyHC-Q ${ }^{403}$ mRNA in the heart (38) and skeletal muscles (39) of human patients with HCM. In brief, RNA was extracted from left ventricle, left atrium, skeletal muscle, aorta, lungs, liver, and spleen of transgenic and NLM rabbits by guanidinium thiocyanate method (36) to characterize expression pattern of the endogenous $\beta$-MyHC mRNA. To detect expression of the endogenous $\beta$-MyHC mRNA in different tissues, RT-PCR was performed on total RNA extracts using RT primer 5'-CTGCTGCAGCTTCTCGTTGGTG- $3^{\prime}$ and PCR primers (forward: 5'-AACAGAAGCAGCGGGAGGAGC-3' and reverse: the same as the RT primer) as described previously $(35,36)$. The expected size of the RT-PCR product was $368 \mathrm{bp}$. To detect expression of the transgene $\beta$ MyHC mRNA in noncardiac tissues, RT-PCR was performed using a transgenic-specific oligonucleotide primers. The sequences of RT and forward primers were: $5^{\prime}$-GCTGTTGAAATCGAAGATCTCG-3' (nucleotides $1502-1481$ of the $\beta$-MyHC cDNA); $5^{\prime}$-TGGAAACATGAAGTTCAAGCT-3' (nucleotides 1162-1183 of the $\beta$ $\mathrm{MyHC}$ cDNA) (31), respectively, and the reverse primer was the same as the RT primer. The expected size of the PCR product was $340 \mathrm{bp}$.

High-resolution 2-dimensional gel electrophoresis. To detect expression of the transgene protein in the heart, myofibrillar protein was extracted and subjected to isoelectric focusing (IEF) followed by SDS-PAGE and immunoblotting. Myofibrillar protein was extracted as described previously (36) with minor modifications. In brief, approximately $100-\mathrm{mg}$ aliquots of left ventricular myocardium were washed 3 times with ice-cold relaxing (RS) buffer $(80 \mathrm{mM} \mathrm{KCl}$, $10 \mathrm{mM} \mathrm{MgCl}_{2}, 1 \mathrm{mM}$ EDTA, $5 \mathrm{mM}$ ATP, $6.6 \mathrm{mM}$ potassium phosphate $[\mathrm{pH} 6.35]$, and protease inhibitors aprotinin $[1 \mu \mathrm{g} / \mathrm{mL}]$, pepstatin $\mathrm{A}[1 \mu \mathrm{g} / \mathrm{mL}]$ and PMSF $[100 \mu \mathrm{g} / \mathrm{mL}])$. Myocardial tissues were homogenized in $1 \mathrm{~mL}$ of RS buffer to which $0.5 \mathrm{M}$ sucrose, $0.5 \%$ Triton- $\mathrm{X} 100$, and $1 \mathrm{mM}$ DTT were added, in a glass-homogenizer. Homogenization was repeated twice, and the supernatants were subjected to sequential centrifugation at 6,000 and $15,000 \mathrm{~g}$ for 30 minutes each at $4^{\circ} \mathrm{C}$. The final pellets containing myofibrillar proteins were lysed in a buffer containing $2 \%$ Triton X-100, $50 \mathrm{mM}$ Tris $\mathrm{HCl}$, and $5 \mathrm{mM} \mathrm{BME}$ in RS buffer. Concentration of the extracted myofibrillar protein was determined by a spectrophotometer using a protein assay kit (Bio-Rad Laboratories).

To perform IEF, 4 glass capillary tubes, equal in length, per each sample, were cast with acrylamide gel monomer solution $(9.2 \mathrm{M}$ urea, $4 \%$ acrylamide, $2.0 \%$ Triton X-100, 1.6\% Bio-Lyte 5/7 ampholyte, 0.4\% BioLyte $3 / 10$ ampholyte, $0.01 \%$ ammonium persulfate and $0.1 \%$ TEMED). After polymerization, capillary tubes were mounted vertically in an electrophoresis chamber (Bio-Rad Laboratories), thoroughly degassed, and set for pre-electrophoresis. Approximately $20-\mu \mathrm{g}$ aliquots of each myofibrillar protein extract were mixed with an equal volume of the sample loading buffer $(9.5 \mathrm{M}$ urea, $2.0 \%$ Triton X-100, 5\% BME, $1.6 \%$ Bio-Lyte $5 / 7$, and $0.4 \%$ Bio-Lyte $3 / 10$ ) and, after incubation at room temperature for 10 minutes, were loaded onto the sample 
reservoirs. The reservoirs were filled with the overlay buffer $(9.0 \mathrm{M}$ urea, $0.8 \%$ Bio-Lyte 5/7, 0.2\% Bio-Lyte $3 / 10$, and $0.05 \%$ Bromophenol blue), and a $\mathrm{pH}$ gradient was generated using $100 \mathrm{mM} \mathrm{NaOH}(\mathrm{pH} 11.4)$ and $10 \mathrm{mM} \mathrm{H} 3 \mathrm{PO} 4$ ( $\mathrm{pH}$ 2.4). Electrophoresis was performed at $500 \mathrm{~V}$ for 10 minutes and then at $750 \mathrm{~V}$ for 4 hours. After completion of the first-dimension elec-

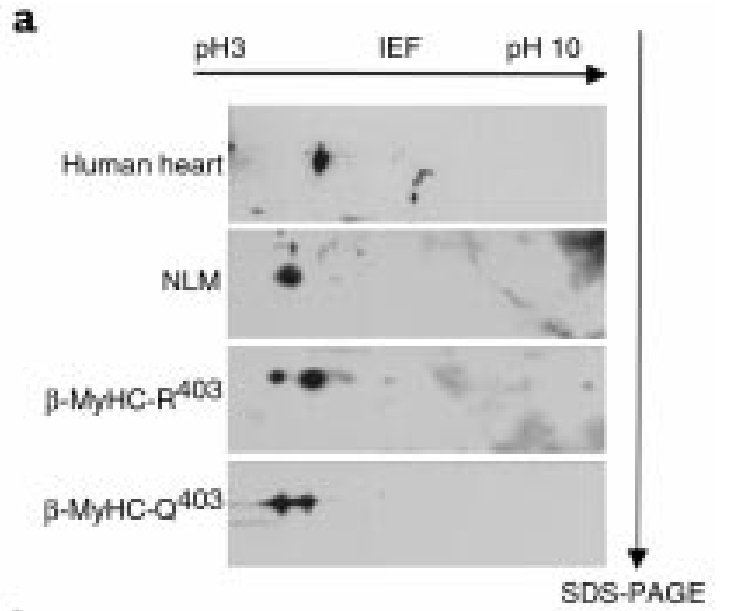

b

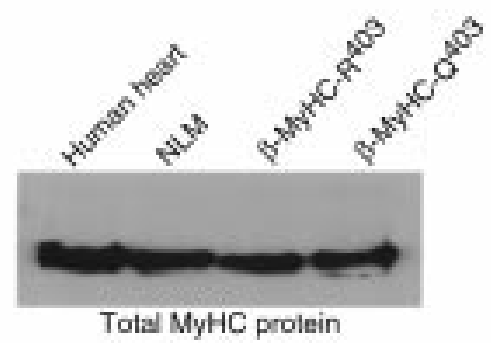

Figure 3

Detection of expression of transgene protein in the heart. (a) Detection of expression of the transgene and endogenous $\beta-\mathrm{MyHC}$ proteins by high-resolution 2-dimensional gel electrophoresis in conjunction with immunoblotting using pan-specific antisarcomeric myosin mAb MF20. Myofibrillar protein extracts from human (labeled as human heart) and nontransgenic rabbits (labeled as NLM) hearts were included as controls. Myofibrillar protein extracts from a wild-type transgenic rabbit ( $\beta$-MyHC- $\mathrm{R}^{403}$ ) and a mutant transgenic rabbit $\left(\beta-\mathrm{MyHC}-\mathrm{Q}^{403}\right)$ were used to separate transgene and endogenous $\beta-\mathrm{MyHC}$ proteins by IEF and to detect by immunoblotting. As shown, a single 220-kDa band is present in panels representing myofibrillar protein extracts from human and NLM hearts. In contrast, in wild-type and mutant transgenic rabbits, 2 bands, both $220 \mathrm{kDa}$ in size, representing endogenous and human $\beta-\mathrm{MyHC}$ proteins were detected by immunoblotting. The proximal band represents expression of the endogenous $\beta$-MyHC protein and the distal band expression of the transgene protein. As shown, expression level of the transgene protein was higher than the endogenous in the wild-type transgenic (55\% of the total $\beta-\mathrm{MyHC}$ pool) and lower than the endogenous in the mutant transgenic (41\% of the total $\beta$-MyHC-pool) rabbits. (b) Immunoblot of total $\mathrm{MyHC}$ protein in the heart detected using mAb MF20. Human heart is included as a positive control and a nontransgenic rabbit (NLM) as a negative control. As shown, the total $\mathrm{MyHC}$ protein pool was not significantly different among NLM, wild-type ( $\left.\beta-\mathrm{MyHC} \mathrm{R}^{403}\right)$, and mutant $(\beta$ $\mathrm{MyHC}-\mathrm{Q}^{403}$ ) transgenic rabbits. trophoresis, capillary tubes were removed and gels containing the samples were ejected, loaded onto 1mm-thick $12 \%$ SDS nondenaturing polyacrylamide slab gels, and subjected to second-dimension electrophoresis. The separated proteins were transferred to PVDF (Bio-Rad Laboratories) membranes and incubated with a blocking buffer $(0.1 \%$ Tween- $20,5 \%$ nonfat dry milk in $1 \times$ PBS). The membranes were treated with antimyosin mAb MF20 (Developmental Studies Hybridoma Bank, University of Iowa, Iowa City, Iowa, USA) at a dilution of 1:50 for 60 minutes at room temperature. Membranes were subsequently exposed to a 1:10,000 dilution of goat anti-mouse horseradish peroxidase conjugate for 60 minutes. Signals were detected by chemiluminescence per recommendation of the manufacturer (Bio-Rad Laboratories).

To detect and quantify expression levels of total $\mathrm{MyHC}$ (endogenous and transgene) proteins in the transgenic rabbit myocardium, $20-\mu \mathrm{g}$ aliquots of myofibrillar protein extracts were loaded onto $12 \%$ nondenaturing SDS-polyacrylamide gels and subjected to electrophoresis (33). After transfer of the proteins to nylon membranes, immunoblotting was performed using pan-specific antisarcomeric myosin mAb MF20 as already described here.

M-mode and 2-dimensional echocardiography: M-mode and 2-dimensional echocardiography were performed using an echocardiography machine equipped with a variable frequency $(2.5-7 \mathrm{MHz})$ transducer and analyzed by an experienced echocardiographer (MQ) who was blinded to the genotype. Adult male and female rabbits 12-24 months of age were anesthetized by intramuscular injection of $0.5 \mathrm{~mL} / \mathrm{kg}$ body weight of a combination of ketamine ( $42.8 \mathrm{mg})$, xylazine $(8.6 \mathrm{mg})$, and acepromazine $(1.4 \mathrm{mg})$. Skin fur in the precordial and substernal regions was shaved and moistened, and images were obtained with rabbits positioned in left lateral decubitus. Interventricular septal thickness (ST), posterior wall thickness (PWT), left ventricular (LV) mass, LV end diastolic diameter (LVEDD), and LV end systolic diameter (LVESD) were measured in M-mode images, guided by 2 -dimensional images, in $4 \mathrm{NLM}, 5$ wild-type ( $\beta$-MyHC$\mathrm{R}^{403}$ ), and 10 mutant ( $\beta$-MyHC-Q $\left.{ }^{403}\right)$ transgenic rabbits. LV mass was calculated as follows: LV mass $=[($ LVEDD $\left.+\mathrm{PWT}+\mathrm{ST})^{3}-(\mathrm{LVEDD})^{3}\right] \times 1.04(40) . \mathrm{LV}$ systolic function was assessed by calculating fractional shortening as follows: [(LVEDD-LVESD)/LVEDD] × 100 .

Histological studies. To determine whether expression of the mutant $\beta-\mathrm{MyHC}-\mathrm{Q}^{403}$ protein leads to cardiac myocyte disarray, the phenotypic hallmark of HCM in humans (3), hearts were perfusion fixed with 3.5\% paraformaldehyde, and the ventricular myocardium was sectioned into 2-mm-thick slices parallel to the atrioventricular groove. After paraffin embedding, $5-\mu \mathrm{m}$ thin myocardial sections were prepared and stained with $\mathrm{H} \& \mathrm{E}$ and examined under direct light microscopy. Ten sections per rabbit and a total of 6 NLM, 5 wild-type, and 6 mutant $\beta$-MyHC-Q ${ }^{403}$ rabbits were examined.

Myocyte disarray was defined as bundles of myocytes 
that were aligned perpendicularly or obliquely to each other or were interspersed in different directions (41-43). Minor variations in the alignment of myocytes were considered branching and not true disarray. Areas of myocardium at the junctions of interventricular septum with the right or left ventricles, or near the blood vessels, and near the trabeculations were excluded from analysis. In addition, areas of the myocardium that were cut transversally were also excluded. The extent of myocyte disarray was calculated by digital planimetry.

To determine whether the $\beta$-MyHC- $\mathrm{Q}^{403}$ transgenic rabbits also exhibited increased interstitial collagen, 10 thin myocardial sections per rabbit were stained by picrosirius red staining. This technique is based on the selective binding of Sirius redF3BA with collagen and is a more robust technique for precise quantification of the tissue collagen content (44). In brief, sections were stained with $0.1 \%$ Sirius Red F3BA in saturated aqueous picric acid for 10 minutes after treatment with $0.2 \%$ phosphomolbdic acid. The interstitial collagen content was measured by eluding the dye with $\mathrm{NaOH}-m e t h a n o l$ and measuring the absorbency at 540 , and the amount of protein was calculated by measuring the absorbency at $605 \mathrm{~nm}$.

Human patients with HCM also display, albeit less commonly, myofibrillar disarray (3). To detect whether $\beta$-MyHC- $\mathrm{Q}^{403}$ transgenic rabbits also exhibit myofibrillar disarray, 5 thin sections of the ventricular myocardium per each rabbit were examined by immunofluorescence microcopy (36). In brief, thin sections were permeabilized through incubation with gradient of ethanol concentrations and then were incubated with $10 \%$ goat serum for 1 hour. After washing, sections were treated with antisarcomeric myosin mouse mAb MF-20 at the concentration of 1:20. Then, sections were washed and incubated with a rhodamine-conjugate, affinity-purified goat antimouse IgG $\mathrm{F}(\mathrm{ab})_{2}$ fragment (Boehringer Mannheim Co., Indianapolis, Indiana, USA) at the concentration of $1: 10,000$ as the secondary antibody. Finally, nuclei were stained by incubating the slides in a $200 \mathrm{ng} / \mathrm{mL}$ solution of Hoechst 33258 dye for 5 minutes.

Survival. Total survival (all cause mortality) in each group was assessed by constructing Kaplan-Meier survival curves for all liveborn rabbits. Newborn bunnies that died within the first few days of birth were genotyped and included in the analysis as well. Bunnies that died from cannibalism (by the mother) and that were stillborn were not included in the analysis.

Statistical analysis. Continuous variables were expressed as mean \pm SD and their differences among the 3 groups were compared by ANOVA. Variables that were unsuited for ANOVA because of inequality of variance were analyzed by the Kruskal-Wallis test. Kaplan-Meier survival curves were compared by log-rank test.

\section{Results}

$\beta$-MyHC transgenes. Schematic diagrams of the wild-type $\left(\mathrm{R}^{403}\right)$ and mutant $\left(\mathrm{Q}^{403}\right)$ transgenes are shown in Figure
1. Sequencing of the transgenes confirmed the presence of $\mathrm{G} \rightarrow \mathrm{A}$ substitution in coding nucleotide 1208 in exon 13 of the $\beta-\mathrm{MyHC}$, which corresponds to the $\mathrm{R}^{403} \mathrm{Q}$ mutation (31). The wild-type and mutant cDNAs have been shown to code for full-length $\beta$-MyHC proteins in previous in vitro experiments (33). The murine $\beta-\mathrm{MyHC}$ promoter (a shorter 5.6-kb fragment) has been shown to confer high levels of expression in the heart and slow skeletal muscle fibers (45-47), tissues where the $\beta$ $\mathrm{MyHC}$ is naturally expressed.

Generation, identification, and establishment of transgenic rabbit lines. Successful generation of transgenic rabbit lines required extensive efforts and was compounded by a high rate of variability in the number of fertilized zygotes recovered from each donor rabbit, a low pregnancy rate, and a relatively high rate of neonatal mortality, including cannibalism. The total number of donor rabbits, fertilized zygotes, implanted zygotes, and recipient rabbits; the pregnancy rate; and the number of transgenic lines are shown in Table 1. Eleven transgenic bunnies were born, and 4 (2 carrying the $\beta$ -

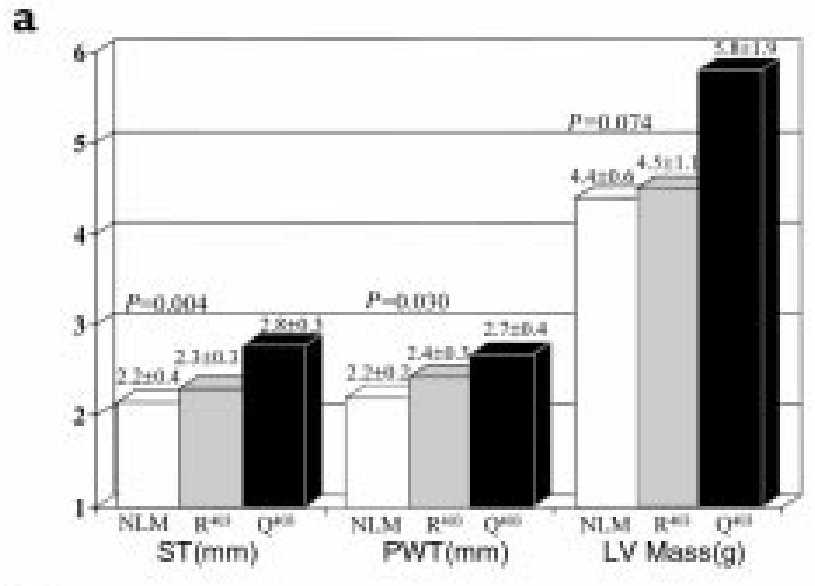

b

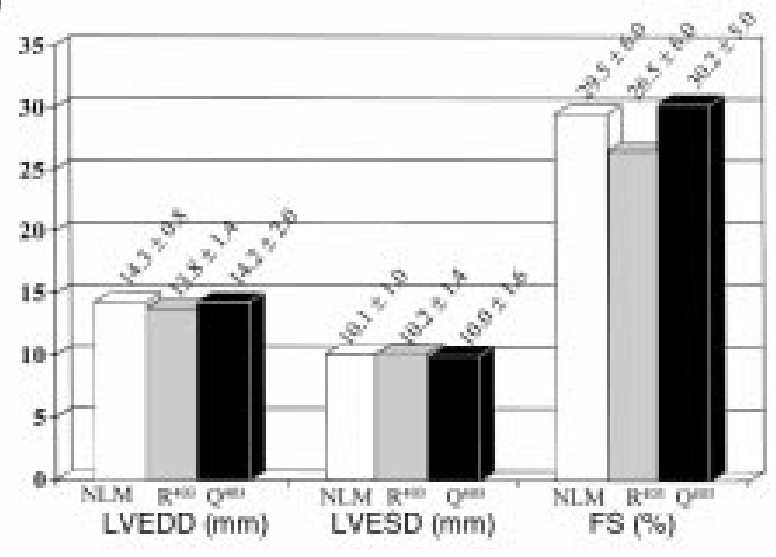

Figure 4

Left ventricular wall thickness, dimensions, and function. (a) Mean interventricular septal thickness (ST), posterior wall thickness (PWT), and left ventricular mass (LV Mass) in nontransgenic (NLM), wild-type $\left(\mathrm{R}^{403}\right)$, and mutant $\left(\mathrm{Q}^{403}\right)$ transgenic rabbits. (b) Left ventricular end diastolic diameter (LVEDD), end systolic diameter (LVESD), and percent fractional shortening (FS) in the 3 groups. Values are mean \pm SD. 
NLM
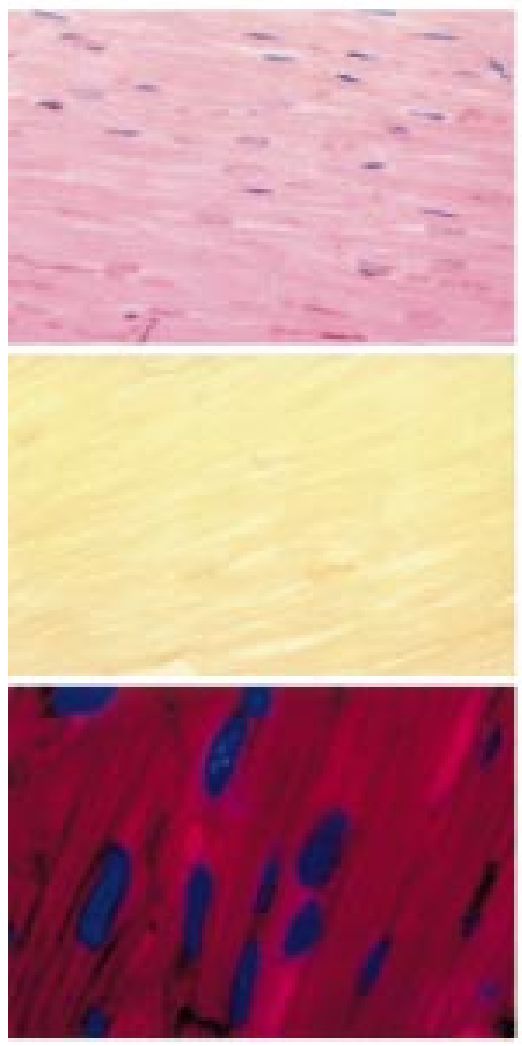

$\beta-\mathrm{MyHC}-\mathrm{R}^{403}$
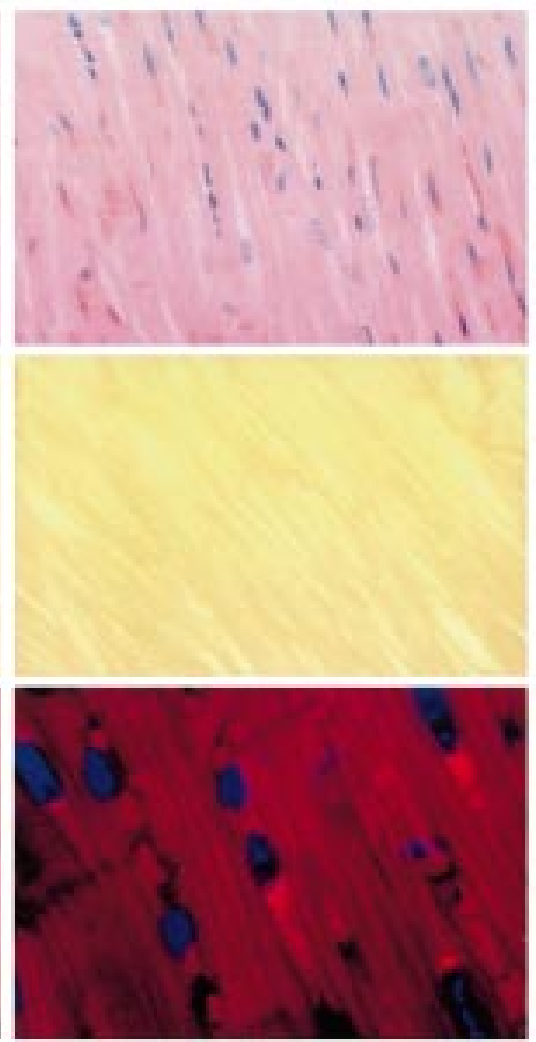

B-MyHC-Q403

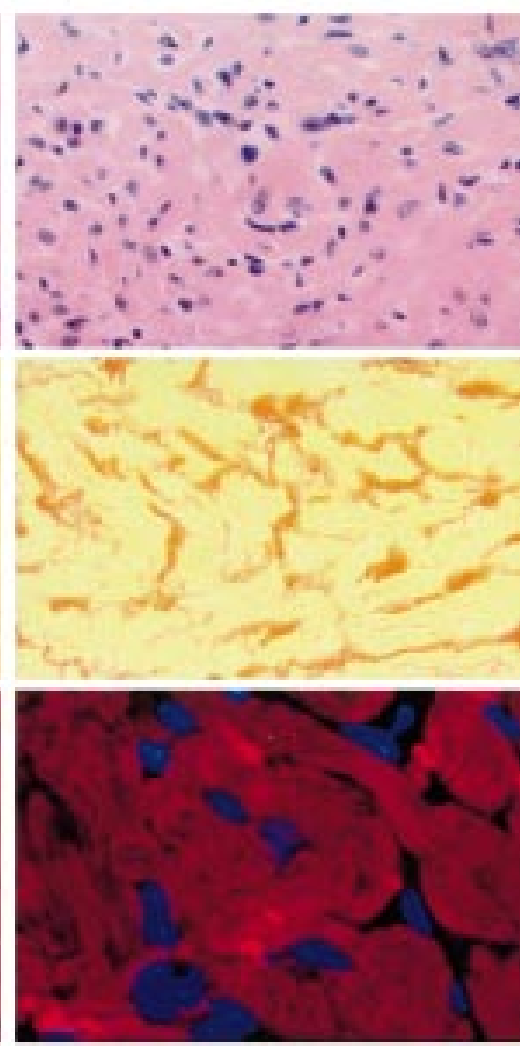

\section{Figure 5}

Histological phenotypes: H\&E staining of myocardial sections are shown in the upper panels, picrosirius red staining in the middle panels, and immunofluorescence staining in the lower panels. NLM represents nontransgenic, $\beta$-MyHC- $\mathrm{R}^{403}$ represents wild-type, and $\beta$-MyHC$\mathrm{Q}^{403 r}$ represents mutant transgenic rabbits. As shown in the upper panels, in $\beta-\mathrm{MyHC}-\mathrm{Q}^{403}$ rabbits, myocytes appear like tangle masses oriented perpendicularly and obliquely to each other, giving a swirl appearance. Pleotrophic and hyperchromatic nuclei are also noted. Myocyte organization was normal in NLM and $\beta-\mathrm{MyHC}-\mathrm{Q}^{403}$ rabbits. The middle panels show increased interstitial collagen (red staining) in $\beta$-MyHC$\mathrm{Q}^{403}$ compared with NLM and $\beta-\mathrm{MyHC}-\mathrm{R}^{403}$. Lower panels represent myofibrillar structure after staining with antimyosin mAb MF-20. Although myofibrils are registered along the long axis of the myocytes in the NLM and $\beta-M y H C-\mathrm{R}^{403}$ transgenic rabbits, they are disorganized and interspersed in multiple directions within the myocytes in the $\beta-\mathrm{MyHC}-\mathrm{Q}^{403}$ rabbits.

MyHC- $\mathrm{R}^{403}$ and 2 carrying the $\beta$-MyHC- $\mathrm{Q}^{403}$ ) lived into adulthood ( 6 months) for which lines were established.

Transgenic bunnies were identified by the presence of a 750-bp transgene-specific product on gel electrophoresis of PCR products and a $1.3 \mathrm{~kb}$ Bam HI transgene-specific fragment on autoradiograms of Southern blots (data not shown). The PCR product was also sequenced, and the presence of the $\mathrm{G}^{1208} \mathrm{~A}$ mutation was confirmed. Copy numbers of the transgenes were 12 and 8 in the mutant lines and 6 and 15 in the wildtype transgenic lines.

Expression of $\beta$-MyHC transgenes $m R N A$ in the heart and noncardiac tissues. Northern blot analysis showed the presence of 6-kb bands in wild-type and mutant transgenic rabbits as shown in Figure 2a, confirming expression of the full-length $\beta$-MyHC transcripts.

Expression profile of the endogenous $\beta-\mathrm{MyHC}$ mRNA in noncardiac tissues was detected by RT-PCR, and the results are shown in Figure $2 \mathrm{~b}$. The size of the RT-PCR product was $368 \mathrm{bp}$, which was detected in the left ventricle, left atrium, and skeletal muscle, but not in the aorta, lungs, liver, and spleen (Figure $2 \mathrm{~b}$ ). As is the case in humans (39), the endogenous $\beta$ - MyHC mRNA is also expressed in skeletal muscles.

Expression profile of the transgene $\beta-\mathrm{MyHC}$ mRNA in noncardiac tissues was also analyzed by RT-PCR, which showed the presence of a 340-bp transgene-specific product (Figure $2 \mathrm{c}$ ) in the left ventricle, left atrium, and skeletal muscles, but not in the aorta, lungs, liver, and spleen. Thus, expression profile of the transgene $\beta$-MyHC mRNA is similar to that of the endogenous $\beta$-MyHC mRNA in the rabbit.

Expression of the transgene protein in the heart. To detect expression of the transgene protein in the heart, in the absence of a transgene-specific antibody, high-resolution 2-dimensional gel electrophoresis in conjunction with immunoblotting was performed. The endogenous and transgene $\mathrm{MyHC}$ proteins were separated by IEF and were detected and quantified by immunoblotting using the pan-specific antisarcomeric myosin $\mathrm{mAb}$ MF20. The results are shown in Figure 3a. The expression level of the transgene protein was less than that of 
endogenous $\beta$-MyHC protein in the mutant transgenic rabbits (41\% of the total MyHC protein pool) and greater than that of the endogenous $\beta$-MyHC protein (55\% of the total MyHC pool) in the wild-type transgenic rabbits (Figure 3a). Total MyHC protein pool (endogenous + transgene) remained unchanged and equal to that in the NLMs as shown in Figure $3 \mathrm{~b}$.

Cardiac hypertrophy in the $\beta-M y H C-Q^{403}$ transgenic rabbit. The results of echocardiographic measurements are shown in Figure 4. The mean $( \pm$ SD) ST, shown in Figure $4 \mathrm{a}$, was greater in the mutant $(2.8 \pm 0.3 \mathrm{~mm} ; n=10)$ compared with wild-type $(2.3 \pm 0.3 \mathrm{~mm} ; n=5)$ transgenic rabbits and NLM $(2.2 \pm 0.4 \mathrm{~mm} ; n=4)$ rabbits $(P$ $=0.004)$. Similarly, PWT and LV mass were also increased in the mutant transgenic rabbits compared with wild-type and NLM rabbits. LVEDD, LVESD, and FS (a measure of systolic function) were not significantly different among the groups (Figure $4 \mathrm{~b}$ ).

Cardiac myocyte and myofibrillar disarray and increased interstitial collagen in the $\beta-M y H C-Q^{403}$ transgenic rabbit. The mean area of myocyte disarray was $12 \pm 7 \%(n=6)$ of the total myocardial sections in the mutant transgenic rabbits. Myocyte disarray was scattered throughout the myocardium. Cardiac myocyte organization was normal in all wild-type $(n=5)$ and $\operatorname{NLM}(n=6)$ rabbits without evidence of pathological myocyte disarray. Representative pictures are shown in Figure 5.

To determine the amount of interstitial collagen content, picrosirius dye was eluted from 10 thin myocardial sections per rabbit, and relative amount of collagen was quantified by a spectrophotometric technique (43). Interstitial collagen content was increased significantly in the mutant $\beta$-MyHC- ${ }^{403}$ compared with wild-type $\beta$-MyHC- ${ }^{403}$ transgenic rabbits or NLMs (Figure 6). The relative ratios of collagen/protein was $63.5 \pm 24 \mu \mathrm{g} / \mathrm{mg}$ in the mutant $(n=6), 24 \pm 16 \mu \mathrm{g} / \mathrm{mg}$ in the wild-type $(n=5)$ transgenic rabbits, and $20 \pm 14$ $\mu \mathrm{g} / \mathrm{mg}$ in NLM rabbits $(\mathrm{F}=9.73 ; P=0.002)$.

Cardiac myofibrillar structure was also examined by an immunofluorescence technique after staining with antisarcomeric myosin mouse mAb MF-20 (Figure 5). Myofibrillar disarray was detected in the mutant $\beta$ MyHC- $\mathrm{Q}^{403}$ transgenic rabbit, whereas myofibrillar structure was normal in all wild type transgenic $(n=5)$ and $\operatorname{NLM}(n=6)$ rabbits.

High incidence of premature death in the homozygous $\beta$ MyHC-Q $Q^{403}$ transgenic rabbit. All cause mortality was higher in the mutant $(20 / 45,44 \%)$ compared with wild-type $(4 / 21,19 \%)$, and $\operatorname{NLM}(7 / 72,10 \%)$ rabbits $\left(\chi^{2}=15.6 ; P=\right.$ 0.0004). Kaplan-Meier survival curves for the entire cohorts of NLM, wild-type, and mutant transgenic rabbits are shown in Figure 6. One 3-month-old wild-type transgenic rabbit and one 7-month-old NLM rabbit died because of pasteurella multocida pneumonia and gastric distention/diarrhea, respectively. Gross and microscopic cardiac examination was normal in these 2 animals. They were included in the Kaplan-Meier total survival analysis. Premature deaths also occurred in 17 mutant transgenic rabbits less than 6 months old and in 3 adult

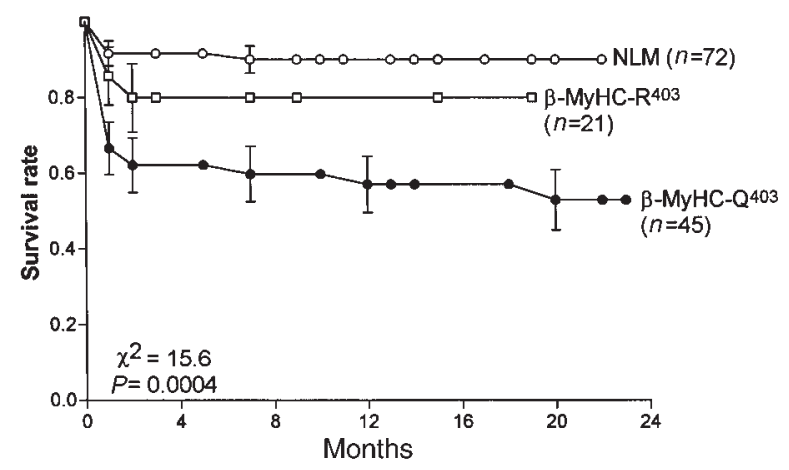

Figure 6

Kaplan-Meier survival curves: 2-year total survival rate of all rabbits in the transgenic lines and nontransgenic littermates (NLM) are depicted. As shown, 2-year survival rate was lower (53\%) in $\beta$-MyHC$\mathrm{Q}^{403}$ compared with $\beta$-MyHC-R ${ }^{403}(80 \%)$ and NLM $(90 \%)(P=$ $0.0004)$. The difference in the survival rates of the wild-type and NLM was not statistically significant.

(> 6 months old) mutant transgenic rabbits. Two adult mutant transgenic rabbits appeared healthy and died from apparent sudden death. Histological examination in these animals showed myocyte and myofibrillar disarray, hypertrophy, and extensive interstitial fibrosis (collagen). The third adult mutant transgenic rabbit appeared ill for 3 weeks before death and had findings of heart failure on necropsy including 4-chamber enlargement and congestion of lungs and abdominal viscera including liver. Histological examination of the heart showed interstitial edema, myocyte disarray, myocyte lysis, myocyte atrophy, and severe fibrosis. None of the mutant transgenic bunnies that died before 6 months of age appeared ill. Necropsy showed myocyte disarray and increased interstitial collagen in 11 bunnies, 4 of which also had myocyte and myofibrillar lysis and increased monocytic infiltrate mimicking myocarditis. One newborn bunny had right lung pneumonia, and in the

\section{Table 1}

Number of animals used to generate transgenic rabbits

\begin{tabular}{cc}
\hline & $n$ \\
Donor rabbits (total) & 192 \\
Zygotes recovered (total) & 2,866 \\
Fertilized zygotes (\%) & $1,978(69)$ \\
Zygotes microinjected (\%) & $1,681(85)$ \\
Zygotes implanted (\%) & $1,530(91 \%)$ \\
Zygotes implanted per recipient rabbit (mean \pm SD) & $16 \pm 4$ \\
Recipient rabbits & 95 \\
Pregnancy rate $(\%)$ & $23(24 \%)$ \\
estation period (mean \pm SD) & $31 \pm 2$ days \\
Bunnies born (total) & 51 \\
Transgene positive (F0) bunnies & 11 \\
Wild-type $\left(\beta-M y H C-R^{403}\right)$ & 5 \\
Mutant $\left(\beta-M y H C-Q^{403}\right)$ & 6 \\
Wild-type $\left(\beta-M y H C-R^{403}\right)$ & 4 \\
Mutant $\left(\beta-M y H C-Q^{403}\right)$ & 2 \\
\end{tabular}


remaining 5 no gross or histological abnormalities were found. Survival analysis after exclusion of 6 mutant transgenic bunnies that had no cardiac pathology showed a 2-year survival rate of $60 \%$, which was significantly lower than that of wild-type transgenic (85\%) and $\operatorname{NLM}(92 \%)$ rabbits $\left(\chi^{2}=10.3 ; P=0.006\right)$.

\section{Discussion}

Expression of the mutant $\beta-\mathrm{MyHC}-\mathrm{Q}^{403}$ protein, known to cause HCM in humans (32), induced gross cardiac hypertrophy, myocyte and myofibrillar disarray, excess interstitial collagen and a high incidence of premature death in transgenic rabbits. LV systolic function and dimensions were within normal limits in the mutant transgenic rabbits. The observed phenotype is virtually identical to that of HCM caused by the $\beta$ MyHC-Q ${ }^{403}$ in humans (2). The wild-type ( $\beta$-MyHC$\mathrm{R}^{403}$ ) transgenic rabbits exhibited no gross or microscopic phenotype of HCM. The combinations of myocardial background of $\beta-\mathrm{MyHC}$, along with the feasibility of high-resolution serial echocardiography, and the expression of comprehensive phenotype of HCM, make the $\beta-\mathrm{MyHC}-\mathrm{Q}^{403}$ transgenic rabbits an ideal model for pathogenetic and therapeutic studies of human HCM. This is particularly important in studying the pathogenesis of human $\mathrm{HCM}$ due to $\beta$ - $\mathrm{MyHC}$ mutations, which accounts for approximately $35-50 \%$ of all cases of human HCM (6).

Despite high level of homology between human and rabbit $\beta$ MyHC proteins $(30,31)$, we were able to separate the transgene (human) from the endogenous (rabbit) $\beta$-MyHC protein by high-resolution 2 -dimensional gel electrophoresis and to quantify their relative expression levels by immunoblotting. Expression of the mutant $\beta$-MyHC- $\mathrm{Q}^{403}$ protein in both transgenic lines was less than that of the endogenous $\beta-\mathrm{MyHC}$ protein, which indicates that the $\beta$-MyHC- $Q^{403}$ protein exerted a dominant-negative effect on cardiac structure in transgenic rabbits. The total MyHC protein pool in transgenic rabbits remained unchanged, a finding that corroborates the previous reports in transgenic mice models expressing sarcomeric proteins $(12,14,16)$. The possibility that expression of the human wild-type $\beta$ MyHC protein in the rabbit heart itself would act as a mutation and induce a phenotype was excluded. The expression level of the wild-type transgenic protein was higher than that of the endogenous $\beta$ - $\mathrm{MyHC}$ protein in the heart, but the total $\mathrm{MyHC}$ protein pool remained unchanged, which indicates substitution of the endogenous protein by the transgene protein. Despite higher levels of expression of the wild-type transgenic protein in the heart, we did not observed any histological features of the HCM phenotype or echocardiographic abnormalities in the wild-type transgenic rabbits. In addition, we have previously shown that expression of wild-type human $\beta$-MyHC in adult feline cardiac myocytes did not induce a phenotype (33).

Cardiac myocyte disarray is considered the pathological hallmark of human HCM (3). However, myocyte disarray can be observed in normal myocardium at areas where myocytes normally converge at acute angles, such as the junctions of the interventricular septum with the right and left ventricles $(41,42)$. These areas were excluded from analysis for disarray. Minor misalignment of the myocytes also was considered branching and not "pathological" disarray. Thus, the increased myocyte disarray observed in the $\beta-\mathrm{MyHC}-\mathrm{Q}^{403}$ rabbits is "pathological" and due to expression of the mutant sarcomeric protein. The mechanism(s) responsible for myocyte disarray in human subjects with HCM and animal models remains to be determined. Whether myocyte disarray is a direct consequence of myofibrillar disarray, is secondary to disruption of the myocardial architecture, or is due to mechanical or biochemical factors remains unknown. The prognostic significance of disarray also remains to be explored.

The high incidence of premature death in the $\beta$ MyHC- $\mathrm{Q}^{403}$ rabbits is also in accord with the high incidence of SCD associated with the $\beta-\mathrm{MyHC}-\mathrm{Q}^{403}$ mutation in human patients $(32,48,49)$. Increased interstitial collagen content, a common feature of HCM in humans and in $\beta-\mathrm{MyHC}-\mathrm{Q}^{403}$ rabbits, is considered a potential culprit for cardiac arrhythmia and SCD (50-52). Increased interstitial collagen can induce slow electrical conduction favoring re-entry arrhythmias (52). Similarly, left ventricular hypertrophy is also known to increase in the risk of SCD in the general population by several fold (53). It is also associated with the risk of SCD in human patients with $\operatorname{HCM}(54,55)$. The interplay between interstitial fibrosis, cardiac hypertrophy, and premature death in humans with HCM and in transgenic animal models is yet to be determined. The $\beta$-MyHC-Q ${ }^{403}$ transgenic rabbit model, by exhibiting both hypertrophy and increased fibrous tissue, should provide an opportunity to delineate the independent role of these phenotypes in susceptibility to SCD in HCM. This is particularly attractive because extensive electrophysiological studies have been performed in rabbits for more than 3 decades (56) and wellcharacterized normal values for comprehensive electrophysiological parameters have been established. The results of such studies can have broad application, as increased interstitial collagen is also a common feature of most forms of heart failure and is possibly responsible for SCD in heart failure (50-52).

The $\beta$-MyHC- $\mathrm{Q}^{403}$ transgenic rabbit model confers several advantages over the existing transgenic mouse models. One major advantage is the similarity in the composition of sarcomeric proteins (24). $\beta$ - $\mathrm{MyHC}$ protein is the predominant protein in the ventricle of humans and rabbits comprising greater than $95 \%$ and greater than $85 \%$ of the total myosin pools, respectively (24). Human and rabbit $\beta$-MyHC proteins are approximately $98 \%$ homologous $(30,31)$, and skinned rabbit and human cardiac myocytes exhibit similar contractile properties (27). This is in contrast to the mouse, in which the $\beta$-MyHC protein is expressed only at very low levels and is less than $5 \%$ of the total myosin 
(24). The $\beta$-MyHC and $\alpha-\mathrm{MyHC}$ proteins exhibit major differences in actin-activated Mg-ATPase activity and cross-bridge cycling rate $(25-29,57,58)$. The rate of ATPase activity is highest for the $\alpha-\mathrm{MyHC}$ (fast isoform) and lowest for the $\beta$-MyHC (slow isoform) (29, $57)$. The velocity of actin-myosin sliding is also fastest for the $\alpha$-MyHC and slowest for the $\beta$-MyHC $(29,57)$. Similarly, the duration of force-transients is shorter for the $\alpha-\mathrm{MyHC}$ and longer for the $\beta-\mathrm{MyHC}$ isoforms $(25$, $26)$. The significance of the composition of the sarcomeric proteins in modulating cardiac function is further emphasized by the results of recent studies in human patients with heart failure $(59,60)$, which showed that upregulation of expression of $\alpha-\mathrm{MyHC}$ proteins was associated with systolic dysfunction. Other advantages of the transgenic rabbit model are reflective of the larger cardiac size, which make the model more suitable for serial noninvasive functional studies such as echocardiography or electrophysiology. In summary, we have expressed the $\beta-\mathrm{MyHC}-\mathrm{Q}^{403}$, known to cause HCM in humans, in the heart of transgenic rabbits and have developed a model that exhibits cardiac hypertrophy, myocyte and myofibrillar disarray, increased interstitial collagen content, and a high incidence of premature death. Thus, the $\beta$-MyHC-Q ${ }^{403}$ transgenic rabbit is a desirable model to study the pathogenesis of human HCM.

\section{Acknowledgments}

This work is supported in part by grants from the National Heart, Lung, and Blood Institute, Specialized Centers of Research (P50-HL42267-01), and an Established Investigator Award (9640133N) from the American Heart Association, National Center, Dallas, Texas.

1. Maron, B.J., et al. 1995. Prevalence of hypertrophic cardiomyopathy in a general population of young adults. Echocardiographic analysis of 4111 subjects in the CARDIA Study. Coronary Artery Risk Development in (Young) Adults. Circulation. 92:785-789.

2. Wigle, E.D., Rakowski, H., Kimball, B.P., and Williams, W.G. 1995. Hypertrophic cardiomyopathy. Clinical spectrum and treatment. Circulation. 92:1680-1692.

3. Ferrans, V.J., and Rodriguez, E.R. 1983. Specificity of light and electron microscopic features of hypertrophic obstructive and nonobstructive cardiomyopathy. Qualitative, quantitative and etiologic aspects. Eur. Heart J. 4(Suppl. F):9-22.

4. Maron, B.J., et al. 1996. Sudden death in young competitive athletes. Clinical, demographic, and pathological profiles. JAMA. 276:199-204.

5. Marian, A.J., and Roberts, R. 1998. Molecular genetic basis of hypertrophic cardiomyopathy: genetic markers for sudden cardiac death. $J$. Cardiovasc. Electrophysiol. 9:88-99.

6. Watkins, H., et al. 1995. Mutations in the genes for cardiac troponin T and alpha-tropomyosin in hypertrophic cardiomyopathy. N. Engl. J. Med. 332:1058-1064.

7. Marian, A.J., and Roberts, R. 1995. Recent advances in the molecular genetics of hypertrophic cardiomyopathy. Circulation. 91:1336-1347.

8. Marian, A.J., and Roberts, R. 2000. Molecular pathogenesis of cardiomyopathies. In Cardiovascular pathology and physiology. 4th ed. N. Sperelakis, editor. Academic Press. San Diego, CA. In press.

9. Marian, A.J., Zhao, G., Seta, Y., Roberts, R., and Yu, Q.T. 1997. Expression of a mutant (Arg92Gln) human cardiac troponin T, known to cause hypertrophic cardiomyopathy, impairs adult cardiac myocyte contractility. Circ. Res. 81:76-85.

10. Rust, E.M., Albayya, F.P., and Metzger, J.M. 1999. Identification of a contractile deficit in adult cardiac myocytes expressing hypertrophic cardiomyopathy-associated mutant troponin $\mathrm{T}$ proteins. J. Clin. Invest. 103:1459-1467.

11. Kim, S.J., et al. 1999. An alpha-cardiac myosin heavy chain gene muta- tion impairs contraction and relaxation function of cardiac myocytes. Am. J. Physiol. 276:H1780-H1787.

12. Oberst, L., et al. 1998. Dominant-negative effect of a mutant cardiac troponin $\mathrm{T}$ on cardiac structure and function in transgenic mice. J. Clin. Invest. 102:1498-1505.

13. Muthuchamy, M., et al. 1999. Mouse model of a familial hypertrophic cardiomyopathy mutation in alpha-tropomyosin manifests cardiac dysfunction. Circ. Res. 85:47-56.

14. Tardiff, J.C., et al. 1998. A truncated cardiac troponin T molecule in transgenic mice suggests multiple cellular mechanisms for familial hypertrophic cardiomyopathy. J. Clin. Invest. 101:2800-2811.

15. Geisterfer-Lowrance, A.A., et al. 1996. A mouse model of familial hypertrophic cardiomyopathy. Science. 272:731-734.

16. Yang, Q., et al. 1998. A mouse model of myosin binding protein C human familial hypertrophic cardiomyopathy. J. Clin. Invest. 102:1292-1300.

17. Vikstrom, K.L., Factor, S.M., and Leinwand, L.A. 1996. Mice expressing mutant myosin heavy chains are a model for familial hypertrophic cardiomyopathy. Mol. Med. 2:556-567.

18. Vemuri, R., et al. 1999. The stretch-activation response may be critical to the proper functioning of the mammalian heart. Proc. Natl. Acad. Sci. USA. 96:1048-1053.

19. Lim D-S, et al. Decreased left ventricular ejection fraction, detected by ${ }^{178} \mathrm{Ta}$ radionuclide angiography, in transgenic mice expressing a mutant cardiac troponin T-G $\ln ^{92}$ : altered function precedes structural abnormalities. J. Mol. Cell. Cardiol. In press.

20. Cohen, M.V., Cooperman, L.B., and Rosenblum, R. 1975. Regional myocardial function in idiopathic hypertrophic subaortic stenosis. An echocardiographic study. Circulation. 52:842-847.

21. Beyar,R. 1995. Hypertrophic cardiomyopathy: functional aspects by tagged magnetic resonance imaging. Adv. Exp. Med. Biol. 382:293-301.

22. Mishiro, Y., et al. 1999. Regional left ventricular myocardial contraction abnormalities and asynchrony in patients with hypertrophic cardiomyopathy evaluated by magnetic resonance spatial modulation of magnetization myocardial tagging. Jpn. Circ. J. 63:442-446.

23. Hirota, Y., et al. 1982. Hypertrophic nononbstructive cardiomyopathy: a precise assessment of hemodynamic characteristics and clinical implications. Am. J. Cardiol. 50:990-997.

24. Swynghedauw, B. 1986. Developmental and functional adaptation of contractile proteins in cardiac and skeletal muscles. Physiol. Rev. 66:710-771.

25. Sugiura, S., et al. 1998. Distinct kinetic properties of cardiac myosin isoforms revealed by in vitro studies. Adv. Exp. Med. Biol. 453:125-130

26. Sugiura, S., et al. 1998. Comparison of unitary displacements and forces between 2 cardiac myosin isoforms by the optical trap technique: molecular basis for cardiac adaptation. Circ. Res. 82:1029-1034.

27. Pagani, E.D., Shemin, R., and Julian, F.J. 1986. Tension-pCa relations of saponin-skinned rabbit and human heart muscle. J. Mol. Cell Cardiol. 18:55-66.

28. Pagani, E.D., and Julian, F.J. 1984. Rabbit papillary muscle myosin isozymes and the velocity of muscle shortening. Circ. Res. 54:586-594.

29. Schwartz, K., et al. 1981. Myosin isoenzymic distribution correlates with speed of myocardial contraction. J. Mol. Cell Cardiol. 13:1071-1075.

30. Kavinsky, C.J., et al. 1984. Analysis of cloned mRNA sequences encoding subfragment 2 and part of subfragment 1 of alpha- and beta-myosin heavy chains of rabbit heart. J. Biol. Chem. 259:2775-2781.

31. Jaenicke, T., et al. 1990. The complete sequence of the human betamyosin heavy chain gene and a comparative analysis of its product. Genomics. 8:194-206.

32. Watkins, H., et al. 1992. Characteristics and prognostic implications of myosin missense mutations in familial hypertrophic cardiomyopathy. N. Engl. J. Med. 326:1108-1114.

33. Marian, A.J., Yu, Q.T., Mann, D.L., Graham, F.L., and Roberts, R. 1995 Expression of a mutation causing hypertrophic cardiomyopathy disrupts sarcomere assembly in adult feline cardiac myocytes. Circ. Res. 77:98-106.

34. Knight, K.L., Spieker-Polet, H., Kazdin, D.S., and Oi, V.T. 1988. Transgenic rabbits with lymphocytic leukemia induced by the c-myc oncogene fused with the immunoglobulin heavy chain enhancer. Proc. Natl. Acad. Sci. USA. 85:3130-3134.

35. Marian, A.J., et al. 1992. Detection of a new mutation in the beta-myosin heavy chain gene in an individual with hypertrophic cardiomyopathy. $J$. Clin. Invest. 90:2156-2165.

36. Yu, Q., Zhao, G., and Marian, A.J. 1999. In vivo short-term expression of a hypertrophic cardiomyopathy mutation in adult rabbit myocardium: myofibrillar incorporation without early disarray. Proc. Assoc. Am. Physicians. $45-56$.

37. Chomczynski, P., and Sacchi, N. 1987. Single-step method of RNA isolation by acid guanidinium thiocyanate- phenol-chloroform extraction. Anal. Biochem. 162:156-159.

38. Perryman, M.B., et al. 1992. Expression of a missense mutation in the messenger RNA for beta-myosin heavy chain in myocardial tissue in 
hypertrophic cardiomyopathy. J. Clin. Invest. 90:271-277.

39. Yu, Q.T., et al. 1993. Hypertrophic cardiomyopathy mutation is expressed in messenger RNA of skeletal as well as cardiac muscle. Circu lation. 87:406-412.

40. Devereux, R.B., and Reichek, N. 1977. Echocardiographic determination of left ventricular mass in man. Anatomic validation of the method. Circulation. 55:613-618.

41. Maron, B.J., Anan, T.J., and Roberts, W.C. 1981. Quantitative analysis of the distribution of cardiac muscle cell disorganization in the left ventricular wall of patients with hypertrophic cardiomyopathy. Circulation. 63:882-894.

42. Maron, B.J., Sato, N., Roberts, W.C., Edwards, J.E., and Chandra, R.S. 1979. Quantitative analysis of cardiac muscle cell disorganization in the ventricular septum. Comparison of fetuses and infants with and without congenital heart disease and patients with hypertrophic cardiomyopathy. Circulation. 60:685-696.

43. Maron, B.J., and Roberts, W.C. 1979. Quantitative analysis of cardiac muscle cell disorganization in the ventricular septum of patients with hypertrophic cardiomyopathy. Circulation. 59:689-706.

44. Lopez-De Leon, A., and Rojkind, M. 1985. A simple micromethod for collagen and total protein determination in formalin-fixed paraffinembedded sections. J. Histochem. Cytochem. 33:737-743.

45. Knotts, S., Sanchez, A., Rindt, H., and Robbins, J. 1996. Developmental Modulation of a beta myosin heavy chain promoter-driven transgene. Dev. Dyn. 206:182-192.

46. Knotts, S., Rindt, H., and Robbins, J. 1995. Position independent expression and developmental regulation is directed by the beta myosin heavy chain gene's $5^{\prime}$ upstream region in transgenic mice. Nucleic Acids Res. 23:3301-3309.

47. Rindt, H., Gulick, J., Knotts, S., Neumann, J., and Robbins, J. 1993. In vivo analysis of the murine beta-myosin heavy chain gene promoter. J. Biol. Chem. 268:5332-5338.

48. Marian, A.J., et al. 1995. Sudden cardiac death in hypertrophic cardiomyopathy. Variability in phenotypic expression of beta-myosin heavy chain mutations. Eur. Heart J. 16:368-376.
49. Epstein, N.D., Cohn, G.M., Cyran, F., and Fananapazir, L. 1992. Differences in clinical expression of hypertrophic cardiomyopathy associated with two distinct mutations in the beta-myosin heavy chain gene. A 908Leu - Val mutation and a 403Arg - Gln mutation. Circulation. 86:345-352.

50. Assayag, P., et al. 1997. Compensated cardiac hypertrophy: arrhythmogenicity and the new myocardial phenotype. I. Fibrosis. Cardiovasc. Res. 34:439-444.

51. Wu, T.J., et al. 1998. Characteristics of wave fronts during ventricular fibrillation in human hearts with dilated cardiomyopathy: role of increased fibrosis in the generation of reentry. J. Am. Coll. Cardiol. 32:187-196.

52. La Vecchia, L., et al. 1998. Ventricular late potentials, interstitial fibrosis, and right ventricular function in patients with ventricular tachycardia and normal left ventricular function. Am. J. Cardiol. 81:790-792.

53. Frohlich, E.D. 1998. Left ventricular hypertrophy and sudden death. J. AM. Coll. Cardiol. 32:1460-1462.

54. Spirito, P., and Maron, B.J. 1990. Relation between extent of left ventricular hypertrophy and occurrence of sudden cardiac death in hypertrophic cardiomyopathy. J. Am. Coll. Cardiol. 15:1552-1526.

55. Abchee, A., and Marian, A.J. 1997. Prognostic significance of beta-myosin heavy chain mutations is reflective of their hypertrophic expressivity in patients with hypertrophic cardiomyopathy. J. Invest. Med. 45:191-196.

56. Janse, M.J., Opthof, T., and Kleber, A.G. 1998. Animal models of cardiac arrhythmias. Cardiovasc. Res. 39:165-177.

57. VanBuren, P., Harris, D.E., Alpert, N.R., and Warshaw, D.M. 1995. Cardiac $\mathrm{V} 1$ and V3 myosins differ in their hydrolytic and mechanical activities in vitro. Circ. Res. 77:439-444.

58. Holubarsch, C., et al. 1985. The economy of isometric force development, myosin isoenzyme pattern and myofibrillar ATPase activity in normal and hypothyroid rat myocardium. Circ. Res. 56:78-86.

59. Nakao, K., Minobe, W., Roden, R., Bristow, M.R., and Leinwand, L.A. 1997. Myosin heavy chain gene expression in human heart failure. J. Clin. Invest. 100:2362-2370.

60. Lowes, B.D., et al. 1997. Changes in gene expression in the intact human heart. Downregulation of alpha-myosin heavy chain in hypertrophied, failing ventricular myocardium. J. Clin. Invest. 100:2315-2324. 